\title{
ANALISIS STATISTICAL QUALITY CONTROL DALAM UPAYA MENGURANGI JUMLAH PRODUK CACAT DI PABRIK ROTI THE LI NO'U BAKERY
}

\author{
Rahmawaty Ahmad ${ }^{1}, \operatorname{Resmawan}^{2}$, Dewi Rahmawaty Isa ${ }^{3}$ \\ ${ }^{1,3}$ Program Studi Statistika, Fakultas Matematika dan IPA, Universitas Negeri Gorontalo \\ ${ }^{2}$ Program Studi Statistika, Fakultas Matematika dan IPA, Universitas Negeri Gorontalo
}

e-mail: nhuuahmad@gmail.com

\begin{abstract}
Abstrak
Pengendalian kualitas merupakan aktivitas teknik dan manajemen dimana mengukur karakteristik kualitas dari produk atau jasa. Pengendalian kualitas statistik (Statistical Quality Control) dapat digunakan untuk menemukan kesalahan produksi yang mengakibatkan produk cacat sehingga dapat diambil tindakan perbaikan lebih lanjut untuk mengatasinya. Tujuan yang akan dicapai dalam penelitian ini adalah untuk menentukan metode Statistic Quality Control (SQC ) dengan diagram pareto, peta kendali, diagram sebab akibat dan analisis $5 \mathrm{~W}+1 \mathrm{H}$ diterapkan pada Pabrik Roti The Li No'u Bakery dalam mengendalikan kualitas untuk meminimalkan produk gagal. Data pada penelitian didapatkan melalui observasi langsung dan wawancara lapangan. Alat analisis data yang digunakan adalah grafik kendali, diagram pareto, diagram sebab akibat dan analisis $5 \mathrm{~W}+$ 1H. Melalui diagram sebab akibat didapatkan faktor utama penyebab kegagalan produk roti di Pabrik Roti The Li No'u Bakery adalah operator/karyawan. Hal ini dikarenakan operator gagal dalam pembuatan produk roti baik tahap persiapan bahan baku, proses produksi dan packaging. Jadi diperlukan pelatihan mengenai pembuatan adonan, cara meletakan roti dan cara pengovenan serta tata tertib karyawan sesuai standarisasi Pabrik Roti The Li No'u Bakery.
\end{abstract}

Kata Kunci: Pengendalian Kualitas, Kegagalan, Produk Cacat, Roti

\begin{abstract}
Quality control is a technical and management activity which measures the quality characteristics of a product or service. Statistical quality control can be used to find production errors that result in defective products so that further corrective action can be taken to overcome them. The objective to be achieved in this research is to determine the Statistical Quality Control (SQC) method with pareto diagrams, control charts, cause and effect diagrams and $5 \mathrm{~W}+1 \mathrm{H}$ analysis applied to The Li No'u Bakery in controlling quality to minimize failed products. The data in this study were obtained through direct observation and field interviews. Data analysis tools used are control charts, pareto diagrams, cause and effect diagrams and $5 \mathrm{~W}+1 \mathrm{H}$ analysis. Through a cause and effect diagram, the main factors causing the failure of bakery products at The Li No'u Bakery are manufacturers/employees. This is because the operator fails in making bakery products both the preparation of raw materials, the production process and packaging. So training is needed on making the dough, how to put bread and how to covenant and employee order according to the standard of The Li No'u Bakery.
\end{abstract}

Keywords: Quality control, Failure, Defective Product, Bread. 


\section{PENDAHULUAN}

Perkembangan ilmu dan kemajuan teknologi di era globalisasi saat ini menyebabkan persaingan yang ketat dalam dunia bisnis. Salah satunya, pada kualitas produk yang dihasilkan oleh sebuah perusahaan dalam bidang industri sehingga unggul dengan pesaing lainnya. Strategi kualitas produk tersebut merupakan faktor keberhasilan bisnis dan peningkatan persaingan posisi bisnis dimulai dengan adanya lingkungan organisasi yang melibatkan para pekerja dalam mengimplementasikan kualitas tersebut. Maka perusahaan perlu menerapkan pengendalian kualitas yang baik karena mampu menekan jumlah produk cacat dan mengukur faktor penyebab dalam perbaikan kualitas. Apabila kecacatan produk terus dibiarkan begitu saja maka akan merugikan perusahaan. Maka dari itu diperlukan pengendalian kualitas statistik. Pengendalian kualitas merupakan salah satu teknik-teknik dalam memantau dan meningkatkan performansi untuk menghasilkan produkyang berkualitas (Triaji 2007). Ada beberapa tujuan pengendalian kualitasyakni peningkatan kepuasan pelanggan, penggunaan biaya yang serendah-rendahnya dan selesai tepat pada waktunya (Heizer and Render 2014).

Produk yang berkualitas memiliki sejumlah kepuasan pelanggan atas penggunaan produk, apabila perusahaan sulit bersaing dalam cost baiknya perusahaan menggunakan kualitas produk atau kualitas layanan yang unggul dalam persaingan (Subiyakto et al. 2017). Kualitas adalah loss to society, yangmaksudnya adalah apabila terjadi penyimpangan dari target, hal inimerupakan fungsi berkurangnya kualitas. Pada sisi lain,berkurangnya kualitas tersebut akan menimbulkan biaya (Taguchi and Konishi 1987).

Kualitas produk yang baik didapatkan dari pengendalian kualitas yang baik pula. Untuk itu, dalam pembuatan produk salah satunya pada pabrik roti The Li No'u Bakery dibutuhkan pengendalian kualitas untuk menjaga agar produk tersebut terjamin kualitasnya dan mampu menekan jumlah produk cacat.

Pabrik Roti TheLi No'u Bakery merupakan salah satu perusahaan yang bergerak dalam bidang industri sejak bulan Agustus 2015 sampai saat ini. Sesuai hasil penelitian awal dengan menggunakan metode wawancara yang dilakukan oleh peneliti dengan pihak pabrik roti The Li No'u Bakery yang bernama Muhammad Kurniansyam Rumansyah bahwa dalam menjalankan bisnisnya selama ini belum menerapkan sistem pengendalian kualitas produksi, sehingga masih banyak jumlah produk cacat atau gagal. Produk cacat atau gagal dapat berpengaruh pada keuntungan yang diperoleh oleh perusahaan karena biaya yang dikeluarkan akan meningkat. Oleh sebab itu perlunya dilakukan pengendalian kualitas statistik. Berdasarkan data yang diperoleh dari Pabrik Roti The Li No'u Bakery jumlah produksi roti dibulan desember 2018 sejumlah 91.132 roti dengan jumlah produk cacat sebesar 839 atau $0.92 \%$. Dari data tersebut dapat dilihat adanya permasalahan pada perusahaan yakni tingginya jumlah produk gagal atau cacat maka peneliti tertarik untuk melakukan penelitian mengenai masalah pengendalian kualitas pada pabrik roti tersebut.

Selama setengah abad terakhir, kualitas dan manajemen kualitas dalam statistik telah mengalami evolusi menjadi yang kini dikenal dengan Total Quality Manajemen (TQM). Secara umum, TQM mempunyai dua komponen yang saling berhubungan, yaitu sistem manajemen dan sistem teknik (Ju Yen et al. 2002). Di bawah payung TQM tersebut terdapat beberapa alat dan teknik yang dapat digunakan untuk memperbaiki kualitas produk dan proses, atau pelayanan. Pengendalian kualitas statistik atau Statistical Quality Control (SQC) ialah salah satu teknik TQM yang digunakan dalam mengelola dan mengendalikan proses dengan melalui penggunaan metode statistik (Besterfield 1998). Teknik penyelesaian permasalahan yang digunakan untuk mengendalikan, memonitor, menganalisis, mengelola, 
dan memperbaiki produk dan proses menggunakan metode-metode statistik disebut dengan pengendalian kualitas statistik (Ariani 2004).

Salah satu penelitian yang menggunakan SQC (Djana and Mayasari 2017) menunjukkan bahwa dengan menggunakan alat bantu statistik berupa Check Sheet dan Grafik Kendali $p$ (Proporsi) dapat mengurangi tingkat kerusakan produksi, menjaga kualitas produk yang dihasilkan dan mengendalikan kualitas Membran dalam pervaporasi Etanol-Air.

Dalam penelitian ini metode SQC yang digunakan untuk pengendalian produk cacat di Pabrik Roti The Li No'u Bakery tidak hanya menggunakan 2 tools melainkan lima tools yakni Check Sheet untuk menganalisis penentuan fakta, Grafik Kendali p untuk menganalisis terkendali atau tidaknya suatu prosesproduksi, Diagram Pareto untuk menganalisis jenis cacat, Diagram Sebab Akibat (Ishikawa) untuk menganalisis faktor utama penyebab cacat serta Analisis $5 \mathrm{~W}+1 \mathrm{H}$ sehingga didapatkan usulan perbaikan yang dapat diterapkan dalam pengendalian produk cacat di Pabrik Roti The Li No'u Bakery.

\section{METODE PENELITIAN}

Penelitian ini dilakukan dilakukan selama 6 bulan dimulai dari bulan juli 2019 sampai dengan desember 20019, yang bertempat di Pabrik roti Te Li No'u Bakery Kabupaten Gorontalo, yang menjadi variabel pada penelitian ini yaitu roti dan kualitas roti. Data penelitian ini yaitu jumlah produksi dan jumlah produk cacat slan selama bulan September 2019. Pengambilan sampel menggunakan teknik purposive sampling. Teknik pengumpulan data yaitu dengan metode wawancara, observasi dan dokumentasi. Metode analis yang digunakan yaitu membuat check sheet, mendeskripsikan data, membuat peta kendali $\mathrm{p}$, membuat diagram pareto, dan mencari factor penyebab menggunakan diagram sebab akibat. 


\section{HASIL DAN PEMBAHASAN}

\subsection{Analisis Penentuan Fakta}

Tabel 1 Check Sheet Jenis Cacat

\begin{tabular}{|c|c|c|c|c|}
\hline \multirow{2}{*}{ Observsi Ke- } & \multicolumn{4}{|c|}{ Jenis Cacat } \\
\hline & Hangus & Peot & Terpotong & Kemasan Terbuka \\
\hline 1 & $\sqrt{ }$ & $\sqrt{ }$ & & \\
\hline 2 & $\sqrt{ }$ & & & \\
\hline 3 & $\sqrt{ }$ & & & $\sqrt{ }$ \\
\hline 4 & $\sqrt{ }$ & $\sqrt{ }$ & & $\sqrt{ }$ \\
\hline 5 & $\sqrt{ }$ & & $\sqrt{ }$ & $\sqrt{ }$ \\
\hline 6 & $\sqrt{ }$ & & $\sqrt{ }$ & $\sqrt{ }$ \\
\hline 7 & $\sqrt{ }$ & & & $\sqrt{ }$ \\
\hline 8 & $\sqrt{ }$ & & & $\sqrt{ }$ \\
\hline 9 & $\sqrt{ }$ & & $\sqrt{ }$ & \\
\hline 10 & $\sqrt{ }$ & $\sqrt{ }$ & & $\sqrt{ }$ \\
\hline 11 & $\sqrt{ }$ & & $\sqrt{ }$ & $\sqrt{ }$ \\
\hline 12 & $\sqrt{ }$ & & & $\sqrt{ }$ \\
\hline 13 & $\sqrt{ }$ & $\sqrt{ }$ & & $\sqrt{ }$ \\
\hline 14 & $\sqrt{ }$ & & & $\sqrt{ }$ \\
\hline 15 & $\sqrt{ }$ & & $\sqrt{ }$ & . \\
\hline 16 & $\sqrt{ }$ & & & $\sqrt{ }$ \\
\hline 17 & $\sqrt{ }$ & & & $\sqrt{ }$ \\
\hline 18 & $\sqrt{ }$ & & & $\sqrt{ }$ \\
\hline 19 & $\sqrt{ }$ & & $\sqrt{ }$ & \\
\hline 20 & $\sqrt{ }$ & & $\sqrt{ }$ & \\
\hline 21 & $\sqrt{ }$ & & & $\sqrt{ }$ \\
\hline 22 & $\sqrt{ }$ & & $\sqrt{ }$ & $\sqrt{ }$ \\
\hline 23 & $\sqrt{ }$ & & & \\
\hline 24 & $\sqrt{ }$ & & & \\
\hline 25 & $\sqrt{ }$ & & $\sqrt{ }$ & \\
\hline
\end{tabular}

Tabel 1 menunjukkan bahwa dari 25 kali observasi di Pabrik The Li No'u Bakery jenis cacat yang terjadi pada roti adalah roti mengalami hangus, peot, terpotong dan kemasan yang terbuka. 


\subsection{Statistik Deskriptif}

Karakteristik jenis cacat pada roti di Pabrik The Li No'u Bakery ditunjukkan pada Tabel 2.

Tabel 2 Jumlah Produksi Roti dan Produk Cacat

\begin{tabular}{|c|c|c|c|c|c|c|}
\hline \multirow{3}{*}{$\begin{array}{c}\text { Observasi } \\
\text { Ke- }\end{array}$} & \multirow{3}{*}{$\underset{\text { Produksi }}{\text { Jumlah }}$} & \multicolumn{4}{|c|}{ Jenis Cacat } & \multirow{3}{*}{$\begin{array}{l}\text { Total } \\
\text { Cacat }\end{array}$} \\
\hline & & \multicolumn{2}{|c|}{ Gagal Produksi } & \multicolumn{2}{|c|}{ Gagal Packaging } & \\
\hline & & Hangus & Peot & $\begin{array}{c}\text { Kemasan } \\
\text { Terbuka }\end{array}$ & Terpotong & \\
\hline 1 & 2145 & 2 & 12 & 0 & 0 & 14 \\
\hline 2 & 2919 & 4 & 0 & 0 & 0 & 4 \\
\hline 3 & 1883 & 6 & 0 & 0 & 2 & 8 \\
\hline 4 & 3505 & 10 & 12 & 0 & 5 & 27 \\
\hline 5 & 3441 & 2 & 0 & 2 & 1 & 5 \\
\hline 6 & 3213 & 12 & 0 & 3 & 12 & 27 \\
\hline 7 & 1742 & 12 & 0 & 0 & 14 & 26 \\
\hline 8 & 2768 & 2 & 0 & 0 & 2 & 4 \\
\hline 9 & 2280 & 1 & 0 & 1 & 0 & 2 \\
\hline 10 & 2228 & 2 & 12 & 0 & 2 & 16 \\
\hline 11 & 2248 & 6 & 0 & 2 & 3 & 11 \\
\hline 12 & 1963 & 1 & 0 & 0 & 4 & 5 \\
\hline 13 & 2882 & 2 & 12 & 0 & 2 & 16 \\
\hline 14 & 2204 & 5 & 0 & 0 & 3 & 8 \\
\hline 15 & 2546 & 5 & 0 & 1 & 0 & 6 \\
\hline 16 & 918 & 1 & 0 & 0 & 2 & 3 \\
\hline 17 & 2548 & 4 & 0 & 0 & 5 & 9 \\
\hline 18 & 2086 & 1 & 0 & 0 & 2 & 3 \\
\hline 19 & 2266 & 1 & 0 & 1 & 0 & 2 \\
\hline 20 & 1633 & 3 & 0 & 1 & 0 & 4 \\
\hline 21 & 1234 & 2 & 0 & 0 & 5 & 7 \\
\hline 22 & 2207 & 2 & 0 & 1 & 2 & 5 \\
\hline 23 & 2476 & 6 & 0 & 0 & 0 & 6 \\
\hline 24 & 2156 & 2 & 0 & 0 & 0 & 2 \\
\hline 25 & 1828 & 4 & 0 & 1 & 0 & 5 \\
\hline Total & 57319 & 98 & 48 & 13 & 66 & 225 \\
\hline $\begin{array}{l}\text { Rata- } \\
\text { Rata }\end{array}$ & 2292.76 & 3.92 & 1.92 & 0.52 & 2.64 & 9 \\
\hline
\end{tabular}

Tabel 2 menunjukkan jumlah produk yang dihasilkan Pabrik The Li Nou Bakery setiap kali produksi tidaklah sama. Rata-rata produk roti yang dihasilkan setiap kali produksi adalah sebanyak 2293 roti pada 25x observasi. Produk roti yang mengalami cacat atau kerusakan adalah sebanyak 225 roti. Adapun jenis cacat atau kerusakan yang paling sering terjadi dalam sebulan adalah roti hangus sebanyak 98 roti sedangkan cacat paling sedikit terjadi adalah kemasan terbuka yakni 13 roti. 


\subsection{Evaluasi Pengendalian Kualitas}

Peta kendali yang menunjukan keadaan tak terkendali (tidak terkontrol) apabila satu atau lebih titik berada diluar batas pengendalian atau titik-titik dalam grafik tersebut menunjukan pola tak random (acak) dan jika terjadi banyak variasi atau penyimpangan suatu produk dapat segera menentukan keputusan apa yang harus diambil (Sugiyono 2017).

Adapun langkah- langkah dalam membuat peta kendali p sebagai berikut:

1. Menghitung Proporsi Kerusakan

$$
p=\frac{P i}{n}
$$

Keterangan:

$\mathrm{Pi} \quad$ : Jumlah gagal dalam sub grup.

n : Jumlah yang diperiksa dalam sub grup.

Sub Grup : : Observasi ke-.

2. Menghitung Garis Tengah

Garis tengah merupakan rata-rata kerusakan produk (p)

Keterangan:

$$
C L=\bar{p}=\frac{\sum p i}{\sum n}
$$

$\bar{p} \quad$ : Rata-rata kerusakan produk

$\sum p i \quad$ : Jumlah total rusak

$\sum n \quad$ : Jumlah total yang diperiksa

3. Mengitung Batas Kendali Atas

$$
U C L=\bar{p}+3 \frac{\sqrt{\bar{p}(1-\bar{p})}}{n}
$$

Keterangan:

$\bar{p}$ : Rata-rata kerusakan produk.

$\mathrm{n}$ : Jumlah produksi.

4. Mengitung Batas Kendali Bawah

$$
L C L=\bar{p}-3 \frac{\sqrt{\bar{p}(1-\bar{p})}}{n}
$$

Keterangan:

$\bar{p}$ : Rata-rata kerusakan produk.

$\mathrm{n}$ : Jumlah produksi.

Jika nilai $\mathrm{LCL}<0$, maka nilai $\mathrm{LCL}=0$ 
Tabel 3 Perhitungan CL, UCL dan LCL

\begin{tabular}{|c|c|c|c|c|c|}
\hline $\begin{array}{c}\text { Observasi } \\
\text { Ke- }\end{array}$ & $\begin{array}{c}\text { Jumlah } \\
\text { Produksi }\end{array}$ & $\begin{array}{l}\text { Total } \\
\text { Cacat }\end{array}$ & $\begin{array}{c}\text { Nilai } \\
\text { Proporsi }\end{array}$ & Nilai UCL & Nilai LCL \\
\hline 1 & 2145 & 14 & 0.006526807 & 0.007976 & 0 \\
\hline 2 & 2919 & 4 & 0.001370332 & 0.007397 & 0.000453301 \\
\hline 3 & 1883 & 8 & 0.00424854 & 0.008248 & 0 \\
\hline 4 & 3505 & 27 & 0.007703281 & 0.007094 & 0.000756817 \\
\hline 5 & 3441 & 5 & 0.001453066 & 0.007123 & 0.000727486 \\
\hline 6 & 3213 & 27 & 0.008403361 & 0.007235 & 0.000615966 \\
\hline 7 & 1742 & 26 & 0.014925373 & 0.00842 & 0 \\
\hline 8 & 2768 & 4 & 0.001445087 & 0.007491 & 0.000359853 \\
\hline 9 & 2280 & 2 & 0.000877193 & 0.007854 & 0 \\
\hline 10 & 2228 & 16 & 0.007181329 & 0.0079 & 0 \\
\hline 11 & 2248 & 11 & 0.004893238 & 0.007882 & 0 \\
\hline 12 & 1963 & 5 & 0.002547122 & 0.008159 & 0 \\
\hline 13 & 2882 & 16 & 0.0055517 & 0.00742 & 0.000431084 \\
\hline 14 & 2204 & 8 & 0.003629764 & 0.007921 & 0 \\
\hline 15 & 2546 & 6 & 0.002356638 & 0.007643 & 0.000207652 \\
\hline 16 & 918 & 3 & 0.003267974 & 0.010117 & 0 \\
\hline 17 & 2548 & 9 & 0.003532182 & 0.007642 & 0.000209111 \\
\hline 18 & 2086 & 3 & 0.001438159 & 0.008033 & 0 \\
\hline 19 & 2266 & 2 & 0.000882613 & 0.007866 & 0 \\
\hline 20 & 1633 & 4 & 0.002449479 & 0.008568 & 0 \\
\hline 21 & 1234 & 7 & 0.005672609 & 0.009266 & 0 \\
\hline 22 & 2207 & 5 & 0.002265519 & 0.007918 & 0 \\
\hline 23 & 2476 & 6 & 0.002423263 & 0.007695 & 0.000155465 \\
\hline 24 & 2156 & 2 & 0.000927644 & 0.007965 & 0 \\
\hline 25 & 1828 & 5 & 0.00273523 & 0.008313 & 0 \\
\hline Total & 57319 & 225 & & & \\
\hline Rata-Rata & 2292.76 & 9 & & & \\
\hline
\end{tabular}

Dari hasil nilai presentase dari setiap subgroup pada Tabel 3, nilai garistengah $(C L)$, nilai batas atas $(U C L)$, dan nilai batas bawah $(L C L)$ diketahui, maka selanjutnya dapat dibuat peta kendali $\mathrm{p}$ yang dapat dilihat pada Gambar 1. 


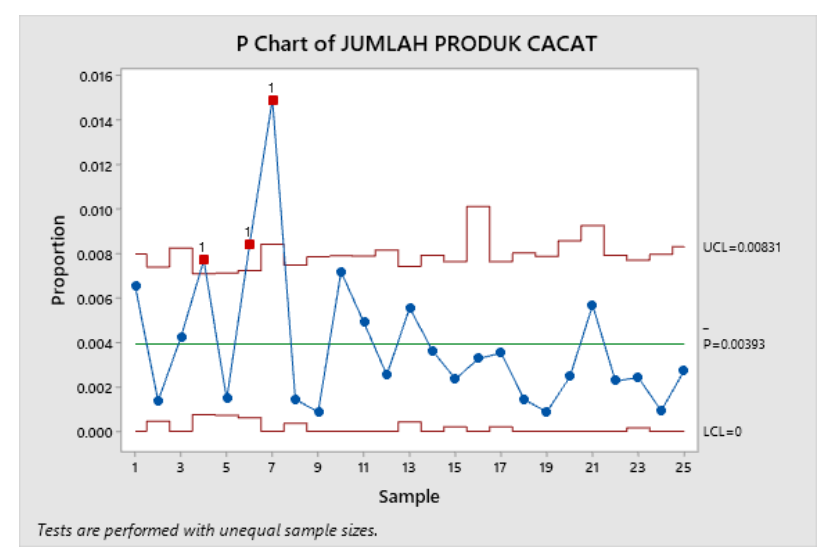

Gambar 1 Grafik Peta Kendali p (p-chart)

Berdasarkan grafik peta kendali pada Gambar 1 dapat dilihat bahwa terdapat tiga titik yang melewati batas kendali atas (UCL) yaitu obervasi ke 4,6 dan 7, sehingga perlu dilakukan revisi/modifikasi pada grafik kendali tersebut dengan cara menghilangkan data observasi ke 4,6 dan 7 yang ditunjukkan pada Gambar 2 untuk memperoleh batas maksimum yang terbaik agar perusahaan tidak akan mengalami kerugian dalam proses produksi.

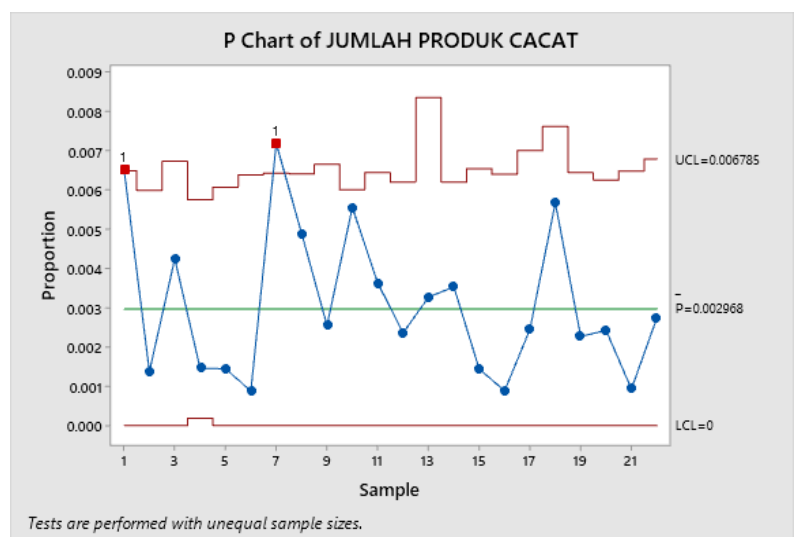

Gambar 2 Grafik Peta Kendali P (p-chart)

Setelah dilakukan modifikasi pada grafik peta kendali yang tampak pada Gambar 2 diperoleh bahwa masih terdapat 2 titik yang berada diluar batas kendali yaitu data observasi ke 1 dan 7 sehingga masih perlu dilakukan modifikasi kembali yang ditunjukkan pada Gambar 3 dengan menghilangkan data observasi ke 1 dan 7.

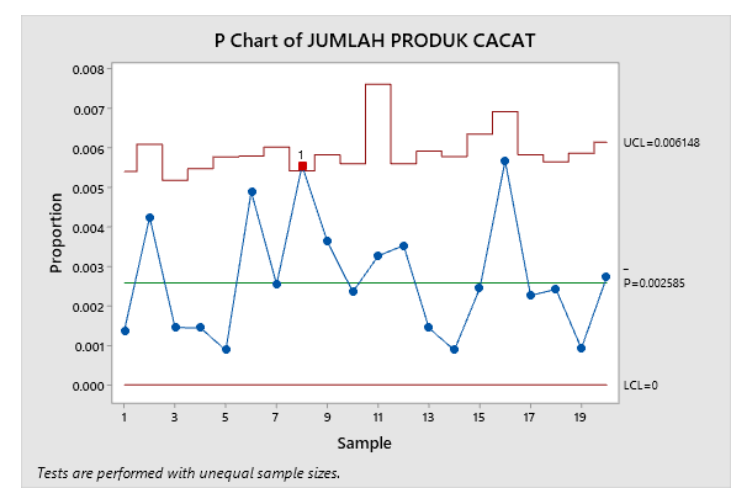

Gambar 3 Grafik Peta Kendali P (p-chart) 
Setelah dilakukan modifikasi kembali pada grafik peta kendali yang tampak pada Gambar 3 diperoleh bahwa masih terdapat 1 titik yang berada diluar batas kendali yaitu data observasi ke 8 sehingga masih perlu dilakukan modifikasi lagi dengan menghilangkan data observasi ke 8. Adapun modifikasi terakhir peta kendali dapat ditunjukan pada Tabel 4.

Tabel 4 Perhitungan $C L, U C L$ dan $L C L$ Setelah Dimodifikasi

\begin{tabular}{|c|c|c|c|}
\hline $\begin{array}{c}\text { Observa } \\
\text { si Ke- }\end{array}$ & $\begin{array}{c}\text { Jumlah } \\
\text { Produksi }\end{array}$ & $\begin{array}{l}\text { Total } \\
\text { Cacat }\end{array}$ & Nilai Proporsi \\
\hline
\end{tabular}

\begin{tabular}{cccccc}
\hline 1 & 2919 & 4 & 0.001370332 & 0.005085 & 0 \\
\hline 2 & 1883 & 8 & 0.00424854 & 0.005748 & 0 \\
\hline 3 & 3441 & 5 & 0.001453066 & 0.004871 & 0 \\
\hline 4 & 2768 & 4 & 0.001445087 & 0.005158 & 0 \\
\hline 5 & 2280 & 2 & 0.000877193 & 0.005441 & 0 \\
\hline 6 & 2248 & 11 & 0.004893238 & 0.005462 & 0 \\
\hline 7 & 1963 & 5 & 0.002547122 & 0.005679 & 0 \\
\hline 8 & 2204 & 8 & 0.003629764 & 0.005493 & 0 \\
\hline 9 & 2546 & 6 & 0.002356638 & 0.005276 & 0 \\
\hline 10 & 918 & 3 & 0.003267974 & 0.007204 & 0 \\
\hline 11 & 2548 & 9 & 0.003532182 & 0.005275 & 0 \\
\hline 12 & 2086 & 3 & 0.001438159 & 0.00558 & 0 \\
\hline 13 & 2266 & 2 & 0.000882613 & 0.00545 & 0 \\
\hline 14 & 1633 & 4 & 0.002449479 & 0.005997 & 0 \\
\hline 15 & 1234 & 7 & 0.005672609 & 0.006541 & 0 \\
\hline 16 & 2207 & 5 & 0.002265519 & 0.005491 & 0 \\
\hline 17 & 2476 & 6 & 0.002423263 & 0.005317 & 0 \\
\hline 18 & 2156 & 2 & 0.000927644 & 0.005528 & 0 \\
\hline 19 & 1828 & 5 & 0.00273523 & 0.005798 & 0 \\
\hline Total & $\mathbf{4 1 6 0 4}$ & $\mathbf{5 8}$ & & & \\
\hline $\begin{array}{c}\text { Rata- } \\
\text { Rata }\end{array}$ & $\mathbf{6 9 3 4}$ & $\mathbf{9 , 6 7}$ & & & \\
\hline & & & & & \\
\hline
\end{tabular}

Dari hasil perhitungan nilai presentase dari setiap subgrup, nilai garis tengah (CL), nilai batas atas (UCL), dan nilai batas bawah (LCL) pada Tabel 4 diketahui, maka selanjutnya dapat dibuat peta kendali p yang dapat dilihat pada Gambar 4. 


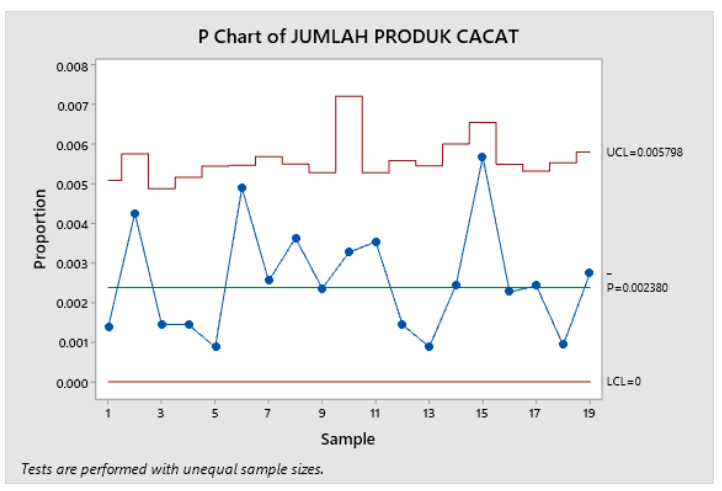

Gambar 4 Grafik Peta Kendali P (p-chart) Setelah Direvisi

Gambar 4 menunjukkan bahwa proporsi jenis cacat maksimal adalah 0,005798 atau 0,5798\% dari jumlah produksi. Berdasarkan grafik peta kendali pada Gambar 4 yang sudah direvisi maka perlu dilakukan pengujian lanjutan untuk melihat penyebab kecacatan atau kerusakan yang terjadi pada proses produksi roti.

\subsection{Identifikasi Faktor Penyebab Kecacatan Proses Produksi}

Berdasarkan gambar pada peta kendali p diatas, dapat dilihat bahwa terdapat data yang berada di luar batas kendali pada titik 1, 4, 6, 7, 10 dan 13, sehingga bisa dikatakan bahwa proses tidak terkendali atau menunjukkan terdapat penyimpangan. Penyimpangan ini mengindikasikan bahwa masih terdapat permasalahan pada proses produksi. Penyimpangan tersebut disebabkan oleh faktor-faktor yang meliputi tenaga kerja, bahan baku, metode/ cara kerja, dan mesin. Oleh sebab itu masih diperlukan analisis lebih lanjut penyebab terjadinya penyimpangan yang sudah terlihat pada peta kendali $\mathrm{p}$ di atas.

\subsection{Klarifikasi Tingkat Kecacatan Proses Produksi}

Dengan diagram pareto, maka dapat diketahui jenis kerusakan yang paling tinggi hingga yang paling rendah. Sehingga dapat membantu menemukan dan menyelesaikan penyebab utama dalam menganalisa masalah yang terjadi. Data jenis kerusakan dan jumlah kerusakan pada hasil produksi roti ditunjukkan pada Tabel 4.

Tabel 5 Persentase Jenis Kerusakan

\begin{tabular}{rlrrr}
\hline No & Jenis Cacat & Total Cacat & Kerusakan & Kumulatif \\
\hline 1 & Roti Hangus & 98 & $43,6 \%$ & $43,6 \%$ \\
\hline 2 & Roti Peot & 66 & $29,3 \%$ & $72,9 \%$ \\
\hline 3 & Kemasan Terbuka & 48 & $21,3 \%$ & $94,2 \%$ \\
\hline 4 & Roti Terpotong & 13 & $5,8 \%$ & $100 \%$ \\
\hline & Total & 225 & $100 \%$ & \\
\hline
\end{tabular}

Berdasarkan hasil perhitungan data pada Tabel 5 maka dapat digambarkan dalam diagram pareto yang menunjukkan perbandingan jenis cacat/kerusakan yang terjadi seperti pada Gambar 5. 


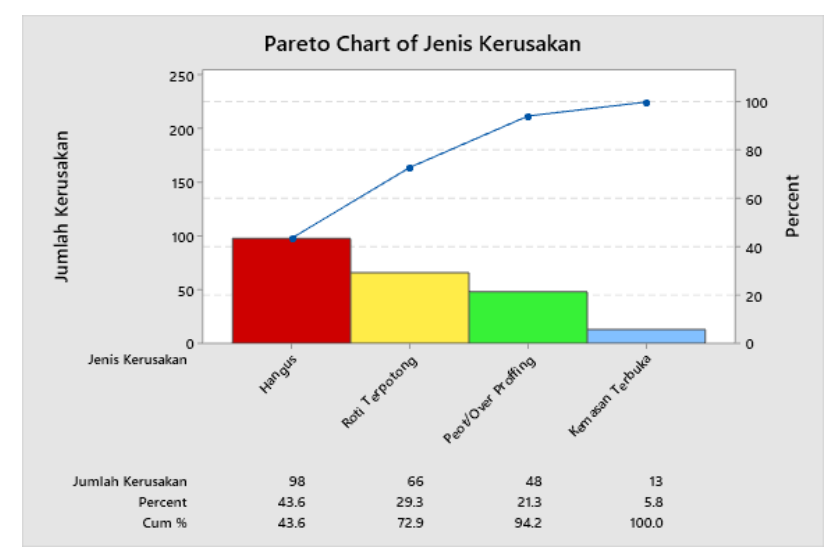

Gambar 5 Diagram Pareto Jenis Kerusakan Roti

Diagram pareto pada Gambar 5 menunjukkan jenis kerusakan yang sering terjadi adalah masalah Hangus dengan jumlah kerusakan sebanyak 98 buah atau 43,6\%. Selanjutnya jenis kerusakan yang sering terjadi kedua yaitu roti terpotong dengan jumlah kerusakan 66 atau 29,3\%. Selanjutnya kerusakan yang sering terjadi ketiga yaitu roti peot dengan jumlah kerusakan 48 buah atau 21,3\%. Selanjutnya jenis kerusakan yang jarang terjadi yaitu kemasan terbuka dengan jumlah kerusakan 13 buah atau 5,8\%.

\subsection{Signifikansi Faktor Penyebab Kecacatan Produk}

Diagram sebab akibat, yang juga dikenal sebagai diagram Ishikawa atau diagram tulang ikan digunakan untuk menganalisis faktor- faktor yang menjadi penyebab kerusakan produk. Faktorfaktor yang mempengaruhi dan menjadi penyebab kerusakan produk secara umum adalah:

a. Bahan Baku, adalah setiap bahan-bahan yang digunakan sebagai bahan utama atau bahanpendukung dalam menghasilkan roti.

b. Sumber daya Manusia, adalah tenaga kerja yang terlibat langsung dalam proses produksi roti.

c. Mesin adalah berbagai peralatan yang digunakan dalam proses produksi

d. Metode produksi, adalah cara kerja dan intruksi yang harus di perhatikan dan di taati oleh tenaga kerja di bagian produksi.

\subsection{Solusi Perbaikan}

Setelah mengetahui jenis dan penyebab kerusakan pada produk paving, maka disusun suatu usulan tindakan perbaikan secara umum sebagai upaya dalam mengurangi setiap kecacatan atau kerusakan dalam memproduksi roti adalah sebagai berikut:

1. Jenis Kerusakan Roti Hangus

Menunjuk salah seorang karyawan profesional khusus mengawasi dan mengecek kinerja setiap operator, khususnyya operator yang mengawaji mesin pemanggangan. Dengan langkah inidiharapkan setiap operator dapat bekerja dengan focus dan dapat meminimalisir kesalahan yang terjadi pada saat pemanggangan. Untuk mengurang kesalahan akibat kesalahan dalam melakukan pencampuran bahan baku, diharapkan dapat mengontrol waktu pencamuran dan menggunakan alat yang dapat menjadikan adonan tercampur secara merta. Untuk bahan baku yang digunakan sebaiknya menggunakan takaran yang telah di tentukan terlebih dahulu, agar bagian produksi tidak akan keliru dalam melakukan pencampuran adonan. Setingan mesin pemanggangan dan perawatan mesin sebagai alat produksi perlu dilakukan perhatikan agar dapat mengurangi kerusakan roti akibat hangus. 


\section{Jenis Kerusakan Roti Peot}

Menunjuk salah seorang karyawan profesional khusus mengawasi dan mengecek kinerja setiap operator, khususnyya operator yang mengakat roti dari mesin pemanggangan. Dengan langkah ini diharapkan siapa saja operator yang mengangkat roti dari mesin pemanggangan dapat bekerja dengan baik dan tidak ceroboh atau ugal-ugalan. Untuk mengurang kesalahan akibat kesalahan dalam melakukan pencampuran bahan baku atau kesalahan dalam proses pengembangan roti. Dengan demikian diharapkan agar sudah tidak ada lagi roti yang peot akibat kelalaian operator maupun kesalahn dalam pencampuran dan pemanggangan.

3. Jenis Kerusakan Roti Terpotong

Kerusakan roti akibat terpotong diakibatkan oleh mesin kemasan yang sering eror dalam saat melakukan pengemasan. Hal ini diakibatkan oleh rol yang sering macet sehingga ini harus menjadi perhatian bersama dari bagian pengemasan khususnya perhatiann dari pemangku kepentinga dalam pabrik roti tersebut. Dari pihak operator bagian produksi diharapkan dapat memeriksa setiap roti yang sementara di kemas.

4. Jenis Kerusakan Kemasan Terbuka

Kerusakan yang diakibatkan oleh kemasan terbuka sering juga terjadi di perusahaan roti sehingga perlu adanya pengawasan yang ekstra pada mesin pengemsan karena saat ini factor kerusakan akibat dari mesing pengemasan. Solusinya adalah dengan memperbaiki mesing pengemsan agar rol untuk plastik pengemasan tidak menjadi masalah lagi pada perusahaan.

\section{KESIMPULAN}

Berdasarkan hasil analisis dan pembahasan, maka dapat diambil bahwa berdasarkan analisis yang dilakukan dapat diketahui bahwa pengendalian kualitas roti yang dihasilkan oleh Pabrik Roti The Li No'u Bakery belum berada dalam batas kendali, karena masih adanya titik yang berada diluar batas kendali. Selanjutnya, jenis cacat roti yang paling sering terjadi adalah roti hangus sehingga jenis cacat yang harus segera ditangani penyebabnya yang pertama yaitu roti hangus kemudian roti terptong, kemudian roti peot dan terakhir roti yang kemasannya terbuka. Selain itu, setiap kerusakan diakibatkan oleh manusia (SDM), dipengaruhi oleh metode produksi serta dipengaruhi oleh mesin, bahan baku dan lingkungan. Manusia merupakan faktor yang paling dominan yang menyebabkan adanya kecacatan produk roti di Pabrik The Li No'u Bakery dibandingkan bahan baku, mesin, metode produksi dan lingkungan produksi. Oleh karena itu, faktor manusia harus lebih diperhatikan agar tidak menimbulkan kerugian yang lebih besar. Setelah dianalisis menggunakan $5 \mathrm{~W}+1 \mathrm{H}$ usulan yang dapat diberikan untuk pengendalian kualitas statistik di Pabrik The Li No'u Bakery adalah sebagai berikut:

a. Memberikan pelatihan kepada para karyawan bagian mengenai pembuatan adonan, cara meletakkan roti dan cara pengovenan sesuai standarisasi produk yang telah ditetapkan serta tata tertib yang berlaku di Pabrik The Li No'u Bakery.

b. Melakukan pengaturan kembali bagian bagian mesin yang dianggap keliru dan tidak sesuai standar pabrik yang ditetapkan dengan bantuan ahli mesin.

c. Mengingatkan operator untuk senantiasa dapat mengawasi proses pengemasan, khususnya bagian roll.

d. Menambah lampu dan kipas dalam ruangan produksi.

e. Memeriksa bahan baku sebelum membelinya, selalu melakukan control bahan baku di bagian gudang pemyimpanan serta memeriksa waktu kadaluarsa bahan baku saat membuat adonan roti. 


\section{DAFTAR PUSTAKA}

Ariani, D. W. (2004), Pengendalian Kualitas Statistik (Pendekatan Kuantitatif dalam Manajemen Kualitas), Yogyakarta: Andi.

Besterfield, D. H. (1998), Quality control, Upper Saddle River, N.J: Prentice Hall.

Djana, M., and Mayasari, R. (2017), "Analisis Pengendalian Kualitas Membran Dalam Pervaporasi Etanol Air Dengan Menggunakan Metode Statistical Quality Control," JISI: Jurnal Integrasi Sistem Industri, 4, 129-138. https://doi.org/10.24853/jisi.4.2.129-138.

Heizer, J., and Render, B. (2014), Operations management: sustainability and supply chain management, Boston: Pearson.

Ju Yen, H., Krumwiede, D. W., and Sheu, C. (2002), "A cross-cultural comparison of top management personality for TQM implementation," Total Quality Management, 13, 335-346. https://doi.org/10.1080/09544120220135219.

Subiyakto, H., Lukmandono, L., and Prabowo, R. (2017), “Analisis Peningkatan Kualitas Produk Precast Concrete Dengan Pendekatan Statistical Process Control dan Quality Function Deployment," Universitas Muhammadiyah Surakarta, pp. 499-506.

Sugiyono, S. (2017), Metode Penelitian Kuantitatif, Bandung: Alfabeta.

Taguchi, G., and Konishi, S. (1987), Orthogonal Arrays and linear graphs: tools for quality engineering, Dearborn, Mich: American Supplier Institute.

Triaji, W. (2007), "Perbaikan Kualitas dengan Metode SPC dan Taguchi untuk Mengurangi cacat Proses Pengepakan Oli Utec 0.8 di P.T Federal Karyatama.," Skripsi, Universitas Bina Nusantara. 